\title{
Drowning following a lightening strike
}

M Vidanapathirana ${ }^{1}$, KS Dahanayake ${ }^{2}$, RHAI Rathnaweera ${ }^{3}$

${ }^{1}$ Senior Lecturer, ${ }^{2}$ Postgraduate trainee, ${ }^{3}$ Lecturer, Department of Forensic Medicine, Faculty of Medicine, Galle.

\section{Case report}

A body of a 30 year old male was found floating in the sea around $5.30 \mathrm{pm}$, on a rainy day with thunder and lightning. When he was last seen alive (at $4.30 \mathrm{pm}$ ), he had been fishing as usual on a rock in the sea, at Ratgama. He was brought to the Teaching Hospital, Karapitiya (THK) and confirmed dead at the OPD.

Examination of clothing - The front of the Tshirt was irregularly torn and the edges were wrinkled from the level of the neck downwards leaving a deficiency of about $30 \mathrm{~cm} \times 20 \mathrm{~cm}$. The back of the T-shirt was stained with blood. The short trousers were intact. Pockets did not contain mobile phones or any metal objects.

External examination - The face was congested, and whitish fine froth was seen on the nostrils and a bloody discharge was seen at the mouth. There were no petechiae in head or face. There were no metal ornaments.

\section{Examination of the injuries}

Injury No. 1 - A linear split laceration 1 x 0.3 $\mathrm{cm}$ was situated on the left eye brow with oozed blood. There was no evidence of burning of skin or singeing of hair.
Injury No. 2 - An irregular fresh $1^{\text {st }}$ degree burns associated with singeing and loss of hair was placed on the back of the head with an irregular fresh laceration measuring $3 \times 0.5 \mathrm{~cm}$ situated on its centre. An underlying scalp contusion measuring $6 \times 4 \mathrm{~cm}$ was seen. There were no injuries involving skull, meningies or brain.

Injury No. 3 - A wide spread continuous $1^{\text {st }}$ and $2^{\text {nd }}$ degree burns were seen over the front of the body from the lower neck and shoulders up to the upper half of both thighs. The upper end of the burn showed some charring. Several other multiple punctate burns ranging from $0.5 \times 0.5 \mathrm{~cm}$ to $3 \times 2 \mathrm{~cm}$ were scattered mainly on the upper abdomen and on the right and left flanks. An ash coloured branching discoloration resembling a $1^{\text {st }}$ degree burn was seen in between and surrounding those burns. The burn injuries were associated with marked singeing of hair (Fig 1).

Internal examination - Trachea \& bronchi contained frothy fluid mixed with blood, sea sand and water. The lungs were seen distended, but neither filled the thoracic cavity nor covered the pericardial sac markedly. No rib markings were seen. The lungs appeared moderately overinflated and purplish blue in colour. They were less crepitant, and while cutting the trachea 
and the main bronchi a moderate amount of frothy fluid came out. The right and left lung were heavy measuring $600 \mathrm{~g}$ and $550 \mathrm{~g}$ in weight respectively. The surface showed multiple subpleural haemorrhages of variable size ranging from $0.3 \times 0.2 \mathrm{~cm}$ to $0.5 \times 0.5 \mathrm{~cm}$ mostly situated on the upper lobes and interlobar fissures. Large amount of blood stained frothy fluid was expressed on compression suggestive of severe pulmonary oedema. The parenchyma showed congestion.

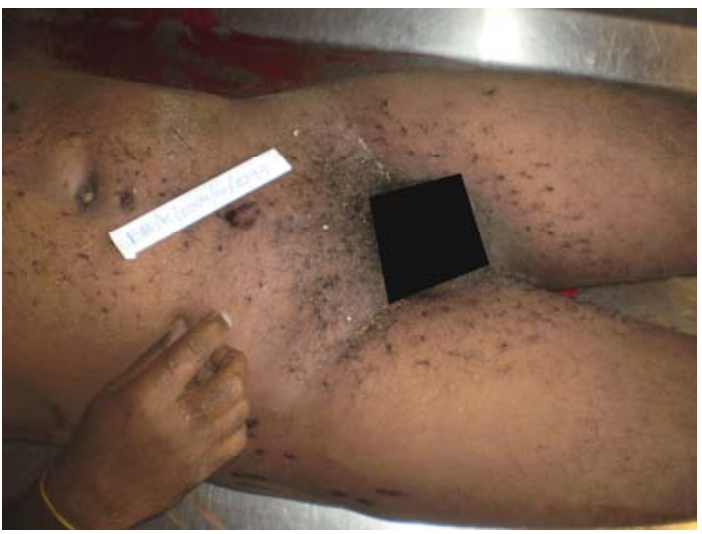

Figure 1 - Singeing of hair and superficial

Investigations- Blood and stomach contents were found negative for alcohol or poison on analysis. Histopathology of Skin (Fig 2) showed, epidermo-dermal separation, charring of cells, nuclear palisading (streaming) and epidermal vacuole formation. Capillary congestion with mild neutrophil infiltration was present around the capillaries.

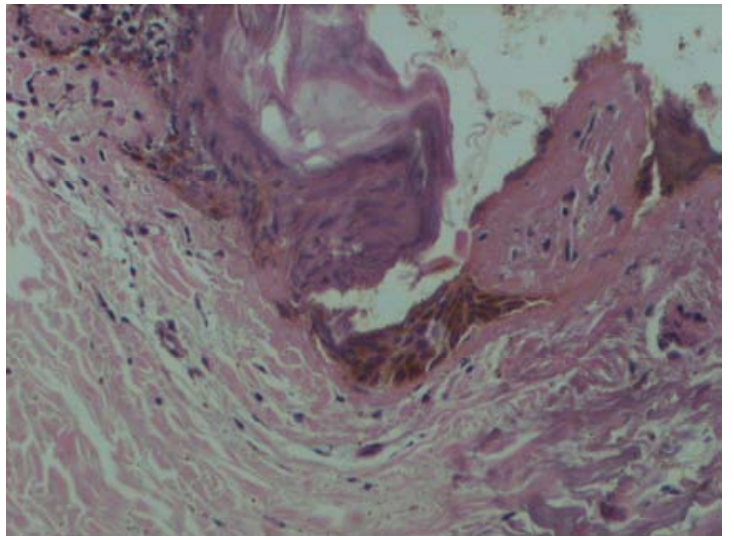

Figure 2 - Photomicrograph of burnt skin
Lungs - Generalized alveolar distension with pale eosinophilic fluid was present. Some discrete alveoli contained filament like intermingling foreign material (Fig 3). Blood vessels were congested.

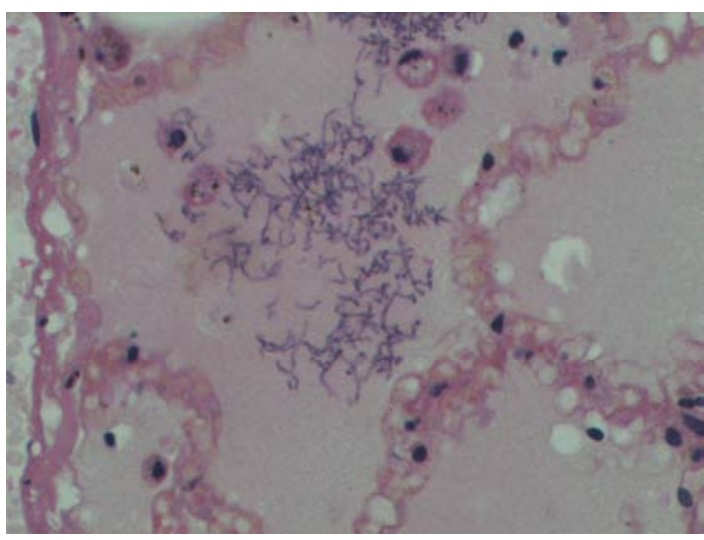

Figure 3 - Photomicrograph of lung Pulmonary oedema and foreign bodies in

\section{Discussion}

\section{Were there evidence of lightening strike?}

i. History - On this particular day, there had been rain with thunder and lightening.

ii. Scene visit - a rock was found in the sea.

iii. Autopsy findings- torn and wrinkled clothing with $1^{\text {st }}$ and $2^{\text {nd }}$ degree diffuse and punctuate burns with singeing of hair with corroborating histological appearance.

These findings confirmed the occurrence of a lightening strike ${ }^{1,2}$.

2. Whether he was alive at the time of entering in to water?

He had following confirmatory evidence of vital reactions while in water.

i. Fine froth at nose and tracheo-bronchial tree suggests drowning.

ii. Histopathology of lungs confirmed the presence of foreign bodies at the level of alveoli with pulmonary oedema and alveolar distension. This indicates breathing while in water at the time of immersion. 
These confirmed the evidence of life at the time of immersion ${ }^{1}$.

\section{Evidence leading to the cause of death?}

i. the fact that the body was found in the sea,

ii. the fine froth seen at the nostrils and mouth ${ }^{1,2,3}$,

iii. blood stained frothy fluid mixed with sand in tracheo-bronchial tree extending to segmental bronchi ${ }^{4}$,

iv. distended, heavy, congested, waterlogged, and oedematous lungs ${ }^{1,2}$,

v. the microscopic evidence of extraneous vegetations in alveoli, the presence of oedema and focal haemorrhages and

vi. negative toxicology screening

confirmed that the cause of death was drowning.

4. He was on the rock fishing. Why did he fall into water?

i. Toxicology screening excluded the possibility of intoxication. ii. There were no autopsy evidence of natural pathology which could have caused incapacitation.

iii. Clear circumstantial and autopsy evidence of injuries caused by lightening strike was present.

The victim could have fallen in to the sea due to the incapacitation caused by the lightening strike. Injuries caused by lightening are by no means always fatal, and only half the victims struck by lightening are killed. Most lighting occurs during April through May in Sri Lanka. Literature review confirmed that there had been no sea water drowning deaths following being incapacitated by lightening. This could be the first ever reported case of sea water drowning of such nature in Sri Lanka.

\section{References}

1. Knight B. and Saukko P. Knight's Forensic Pathology, $3^{\text {rd }}$ edition, Edward Arnold, Oxford, 2004: 527-32.

2. Spitz WU, Spitz \& Fisher's Medico-legal Investigation of Death, Guidelines for the application of Pathology to Crime investigation, $4^{\text {th }}$ ed, Illinois: Charles C Thomas, 2006.

3. DiMio V.J. and DiMaio D, Forensic pathology, $2^{\text {nd }}$ edition, CRC Press, London, 2001. 